\title{
Curriculum Redesign Process for an Industrial Engineering Program Seeking ABET Accreditation
}

\author{
http://dx.doi.org/10.3991/ijep.v5i3.4670 \\ M. Aoudia ${ }^{1}$ and D.A. Abu-Alqahsi ${ }^{1}$ \\ ${ }^{1}$ Industrial Engineering Department, Northern Border University, Arar, Saudi Arabia
}

\begin{abstract}
The objective of this paper is to describe the process to follow by a program seeking ABET accreditation for the redesign of its curriculum. The first step in this process is to clearly identify the reasons behind the need for redesigning the curriculum. These reasons should be originated from three levels of analysis. The high level deals with the review of the Program Educational Objectives. The medium level concerns the assessment and Evaluation of the Student Outcomes. The low level interests the Assessment and Evaluation of the course learning outcomes. The second step is to define all the requirements and constraints that will be used as inputs to the development of concentrations, area of study and courses. The case study presented and discussed in this paper to illustrate the curriculum redesign process is drawn from the Industrial Engineering Department at the Northern Border University (Saudi Arabia).
\end{abstract}

Index Terms-Accreditation, assessment, curriculum redesign, evaluation, industrial engineering.

\section{INTRODUCTION}

The requirement of program objectives and student outcomes in ABET and other accreditation organizations have made the process of design or redesign of undergraduate engineering curricula more complex [1].

Many examples are provided in the literature on the development of an engineering curriculum. Although there is no consensus about the steps to follow in developing or redesigning the curriculum of a program, it is generally agreed that the first step is to consider feedback input from the constituencies for whom the program educational objectives were designed.

Curriculum redesign begins with an identified need for change coming from the constituencies that had not observed the expected knowledge and skills in hired graduates of the program [1].

The authors in [1] suggest a template that curriculum committees can use in curriculum redesign. The basic template is a Table where the program learning outcomes are arranged in the rows of the Table and the columns are the four years of the curriculum. This tool is useful in transforming the feedback from constituencies into a comprehensive curriculum.

In the case of the redesign of the Chemical and Biomolecular Engineering curriculum at the University of Sydney [2], the first step followed was the determination of desired graduate attributes; the second was the design of mechanisms needed to integrate these attributes within the curriculum [2].

The design and implementation of a new industrial \& manufacturing curriculum for the Bachelor and Master degrees have been presented in [3]. An economic explanation is given for the creation of the proposed curriculum. The lack of managerial skills among technology engineers (electrical, mechanical, process...) implies the need for special training during their work time. In return, the engineers from the industrial engineering curriculum did not have specialized skills in a particular technology discipline, so they cannot be hired by small companies because these companies cannot hire one industrial engineer with another technology engineer for doing one job [3]. The proposed curriculum was based on the need of industrial engineers to be equipped with good skills in managing technology, human and financial resources and different types of technology [3].

A model for designing, redesigning, and evaluating programs of systems and computing engineering is defined in [4]. This model is based on the definition of educational goals that facilitate the definition of courses that integrate a set of these desired goals. The methodology proposed in [4] contains eight activities that can facilitate the definition of a new curriculum design based on competences to be developed by graduates.

A holistic for developing a Computer Engineering curriculum approach is proposed in [5]. The proposed approach consists of the following six steps:

- Formulation of objectives;

- Identification of major curriculum areas;

- Construction of core courses;

- Description of electives;

- Integration of laboratory practices and

- Assessment of the curriculum

This paper focuses on the process to follow for redesigning the curriculum for a program seeking ABET accreditation. The suggested process comprises the following steps:

- Identify the need for change

- Define Requirements, Constraints and Benchmarks

- Delimit Concentrations and Areas of Study

- Develop courses (Syllabus, Strategies, Assessment \& Evaluation Methods) 
PAPER

- Plan Courses (Appropriate Timing is crucial)

- Verification

- Validation

- Implementation

- Review

The first step in this process is to clearly identify the reasons behind the need for redesigning the curriculum. These reasons should be originated from three levels of analysis (see Fig. 1). The high level deals with the review of the Program Educational Objectives (PEOs). The medium level concerns the assessment and Evaluation of the Student Outcomes (SOs). The low level interests the Assessment and Evaluation of the Course Learning Outcomes (CLOs). The second step is to define all the requirements and constraints that will be used as inputs to the development of concentrations, area of study and courses. The case study presented and discussed in this paper to illustrate the curriculum redesign process is drawn from the Industrial Engineering (IE) Department at the Northern Border University (Saudi Arabia). This paper focuses only on the first two steps of the suggest curriculum redesign process.

\section{THE NEED FOR CURRICULUM CHANGE}

\section{A. Alignement of Curriculum with Graduate'Attributes}

The IE Department at Northern Border University (NBU) offers a Bachelor of Science in IE. Currently the Department has 8 faculty members and an enrollment of more than 50 undergraduate students. It is part of the college of Engineering which is also home to four other departments: Chemical and Materials Engineering, Civil Engineering, Electrical Engineering and Mechanical Engineering. In 2013, the IE Department produced its first graduates.

The principal constituencies of the IE Program are composed of the following groups:

- Program Students

- Program Alumni

- Program Faculty

- Potential Employers of Program graduates

- Program Advisory Committee

The involvement of the constituencies of the IE Program is a necessary condition for attaining successfully all of the Program Educational Objectives (PEOs).

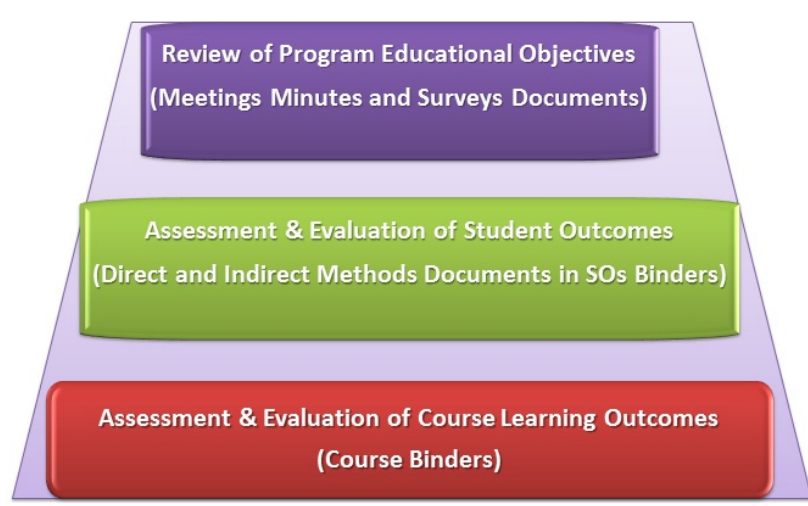

Figure 1. Identifying the reasons for redesigning the Curriculum
The faculty members of the IE Department, in consultation with the constituencies of the IE Program, have established the following PEOs (within three to five years after graduation):

- PEO\#1 (Professionalism): Graduates will contribute meaningfully to meet the needs of various industrial sectors, organizations and societies by using different IE techniques and skills to define and solve realworld problems within ethical, economical and societal perspectives;

- PEO\#2 (Leadership): Graduates will lead their professions and communities by their professional engagement, effective communication and capability to work in multidisciplinary teams;

- PEO\#3 (Lifelong learning): Graduates will be motivated lifelong learners developing their career and professional skills and seeking to update their knowledge in techniques and tools related to IE;

- PEO\#4 (Employability and research): Graduates will be successful in acquiring gainful employment or pursuing graduate programs in IE or related programs.

Program Educational Objectives (PEOs) focus on what graduates are expected to attain within a few years after graduation [6]. The IE Program does not change regularly; so it does not need to have more frequent monitoring cycles to ensure that the program educational objectives are current. For this reason, the educational objectives of the IE Program will be formally reviewed every three years (the first cycle will be started in 2016, i.e. three years after the production of the first batch of IE graduates). The most important issue that will be discussed during this review will be the answer to the following question:

Does the PEOs statement continue to be consistent with the program constituents' needs?

The reason for adopting a periodic review based on a cycle of 3 years is the important change concerning the Criterion 2 and which had been approved by ABET Board of Directors in October 2012 and started to be implemented starting from the 2013-14 accreditation cycle. In this manner, programs are asked to review periodically the consistency of their PEOs with the institutional mission, the program constituents' needs and the ABET criteria and anymore the revision or assessment of their PEOs [7].

Even the cycle for reviewing the PEOs is three years, annual meetings were held, since 2010, for discussing different issues related to the IE Program. Participants to these meetings included the IE Accreditation Committee, IE Curriculum Committee and members of the IE Advisory Committee.

Just after the production of the IE Department's first batch of graduates in 2013, the agenda of these meetings included answering the following questions:

- Is the curriculum of the IE Program still consistent with the PEOs?

- Does the curriculum continue to contribute to the construction of the core attributes of the IE graduates? 
The IE Curriculum Committee and the members of the IE advisory committee had discussed during their meetings, the necessity of redesigning the curriculum in order to reinforce the development of the main student abilities, particularly:

- Strong design capabilities.

- Ability to define, analyze, model and solve problems in an innovative way.

- Development of teamwork and communication skills.

\section{B. Managing Student Outcomes through the Curriculum}

According to the ABET requirements and in order to attain the PEOs within a few years, the IE Program should provide the students with a learning experience that permits them to develop the following Student Outcomes (SOs) by the time of graduation [8]:

a) ability to apply knowledge of mathematics, science, and engineering

b) ability to design and conduct experiments, as well as to analyze and interpret data

c) ability to design a system, component, or process to meet desired needs within realistic constraints such as economic, environmental, social, political, ethical, health and safety, manufacturability, and sustainability

d) ability to function on multidisciplinary teams

e) ability to identify, formulate, and solve engineering problems

f) understanding of professional and ethical responsibility

g) ability to communicate effectively

h) the broad education necessary to understand the impact of engineering solutions in a global, economic, environmental, and societal context

i) a recognition of the need for, and an ability to engage in life-long learning

j) knowledge of contemporary issues

k) ability to use the techniques, skills, and modern engineering tools necessary for engineering practice.

The Agency in the KSA that provides quality assurance of higher education institutions is the National Commission for Academic Accreditation \& Assessment (NCAAA). NCAAA has defined the National Qualifications Framework for Higher Education in KSA. This framework groups the kinds of learning expected of students into the following four domains [9]:

Knowledge, which involves ability to recall, understand and present information, including:

- knowledge of specific facts,

- knowledge of concepts, principles and theories, and

- knowledge of procedures.

Cognitive skills, including the ability to:

- apply conceptual understanding of concepts, principles, theories,
- apply procedures involved in critical thinking and creative problem solving, both when asked to do so, and when faced with unanticipated new situations,

- investigate issues and problems in a field of study using a range of sources and draw valid conclusions.

Interpersonal skills and responsibility, including the ability to:

- take responsibility for their own learning and continuing personal and professional development,

- work effectively in groups and exercise leadership when appropriate,

- act responsibly in personal and professional relationships,

- act ethically and consistently with high moral standards in personal and public forums.

Communication, information technology and numerical skills, including the ability to:

- communicate effectively in oral and written form,

- use information and communications technology, and

- use basic mathematical and statistical techniques.

Psychomotor skills involving manual dexterity are a fifth domain that applies only in some programs.

The ABET SOs can be grouped into the four broad categories defined by NCAAA, as shown in Table I.

The curriculum of the IE Program at Northern Border University is designed to prepare students to achieve the SOs upon graduation and to support the Program Educational Objectives during their careers ( 3 or 5 years after graduation). The curriculum of the IE Program provides IE students with knowledge, skills and abilities that, if attained, the SOs at the time of graduation will be achieved. In turn, these SOs prepare graduates to attain the PEOs.

Course Learning Outcomes (CLOs) are determined for each IE course and mapped to the SOs listed in the course syllabus. The CLOs are assessed in each course by using direct and indirect tools.

TABLE I.

GROUPING THE ABET SOS INTO FOUR CATEGORIES

\begin{tabular}{|c|c|c|c|c|}
\hline SOs & Knowledge & $\begin{array}{c}\text { Cognitive } \\
\text { Skills }\end{array}$ & $\begin{array}{c}\text { Interpersonal } \\
\text { Skills and } \\
\text { Responsibility }\end{array}$ & $\begin{array}{c}\text { Communication } \\
\text {, IT, and } \\
\text { Numerical Skills }\end{array}$ \\
\hline $\mathrm{a}$ & $\sqrt{ }$ & $\sqrt{ }$ & & \\
\hline $\mathrm{b}$ & & $\sqrt{ }$ & & \\
\hline $\mathrm{c}$ & & $\sqrt{ }$ & $\sqrt{ }$ & \\
\hline $\mathrm{d}$ & & & $\sqrt{ }$ & \\
\hline $\mathrm{e}$ & & $\sqrt{ }$ & \\
\hline $\mathrm{f}$ & & & & \\
\hline $\mathrm{g}$ & & & & \\
\hline $\mathrm{h}$ & $\sqrt{ }$ & & & \\
\hline $\mathrm{i}$ & & & & \\
\hline $\mathrm{j}$ & $\sqrt{\mathrm{N}}$ & & & \\
\hline $\mathrm{k}$ & & $\sqrt{ }$ & & \\
\hline
\end{tabular}


The direct tool contains the different graded activities (Quizzes, Homework, Reports, Exams, Final exam, etc.) collected throughout the semester.

The indirect tool used for the assessment of CLOS, is limited to the Course Evaluation Form distributed by faculty to the students at the end of the course. The Course Evaluation Form has three sections: one that deals with the instructor; another that deals with the course itself and the last one concerns the relevant SOs. In the third section of the survey, students were asked to answer the following principal questions using a 5-point scale:

- To which level do you feel that the SO x (listed in the syllabus) was addressed in this course?

- To what degree do you personally feel you achieved the SO x (listed in the syllabus)?

The data from the surveys are submitted to the IE Accreditation Committee for review. Student responses are discussed by the Committee and any recommendations will be discussed by the faculty members of the IE department.

At the end of each semester, the assessment and evaluation of course learning outcomes are maintained and documented in the course file. In the case where a particular SO has not been achieved, all courses linked to this outcome are discussed and considered in the improvement plan particularly if the learning outcomes linked to this $\mathrm{SO}$ are not achieved.

In this manner, the IE curriculum contributes to the attainment of SOs which in turn allows the attainment of program educational objectives.

It is evident that the course evaluations are considered very helpful in identifying potential problems in the IE curriculum in order to address them. However, it was not possible to carry out this procedure in all courses because, as shown by Table II, an important proportion of the courses delivered to the IE students were managed by other Departments.

\section{Assessment and evaluation}

The third reason that supported the necessity of making changes in the curriculum of the IE Program is given by the results of the assessment and evaluation processes of SOs.

\section{1) Direct Assessment}

Faculty members developed a suitable rubric with a few performance indicators (3-5) for each SO. Levels of achievement are specifically defined and graded from 1-4, as follows:

TABLE II.

REQUIREMENTS OF THE OLD IE CURRICULUM

\begin{tabular}{|c|c|c|}
\hline \multicolumn{2}{|c|}{$\begin{array}{l}\text { Students seeking the Bachelor of Sciences in IE degree } \\
\text { at NBU must satisfy the following requirements: }\end{array}$} & $\begin{array}{l}\text { Credit } \\
\text { Hours }\end{array}$ \\
\hline \multicolumn{2}{|c|}{ Preparatory Year } & 27 \\
\hline \multicolumn{2}{|c|}{ University Requirements } & 14 \\
\hline \multicolumn{2}{|c|}{ College Requirements } & 35 \\
\hline \multirow{5}{*}{$\begin{array}{l}\text { Department } \\
\text { Requirements }\end{array}$} & IE Courses & 38 \\
\hline & Non IE Courses & 33 \\
\hline & Elective courses & 9 \\
\hline & Graduation project & 4 \\
\hline & Practical Training & 2 \\
\hline \multicolumn{2}{|c|}{ Total Credit Hours } & 162 \\
\hline
\end{tabular}

1. Not acceptable

2. Below expectations

3. Meets expectations

4. Exceed expectations

This situation justified the necessity of redesigning the curriculum of the IE Program.

Some instructors of the $4^{\text {th }}$ or $5^{\text {th }}$ year level course were assigned (by the IE Accreditation Committee) a number of SOs (no more than 3 ) to assess in their courses.

The instructor selects an assignment (this can be homework or test questions, lab report, article or paper analysis, etc.) in which the students are asked to demonstrate the knowledge, skills or abilities identified in the Performance Criteria. For this assignment, each student's achievement is measured and evaluated by using the appropriate rubric developed for the corresponding SO. The results are then reported in excel spreadsheets by SO and for each student.

At the end of the semester, faculty members submit the summary sheet and a few samples of the student work for each SO they were assigned. These data, in conjunction with copies of the assessment mechanism (homework, exam, etc.) are then placed in the appropriate SO assessment binder, which is maintained in the office of the IE Accreditation Committee at the end of each academic year. The Accreditation Committee reviews the data and provides a report to the Department Chair and faculty with specific concerns and recommendations for improvement, if any. These are then discussed by the full faculty and any decision is voted on.

The results obtained by this direct assessment are summarized in Fig. 2 which illustrates that there is no SO that has been achieved in totality. In Fig.2, the different axes represent the different performance indicators of the ABET SOs (3a-3k).

The assessment data for each performance indicator were collected twice in two different IE courses by using two different tools. For the direct assessment tools, a specific target level of achievement has been established.

\section{Results of Direct Assessment of SOs}

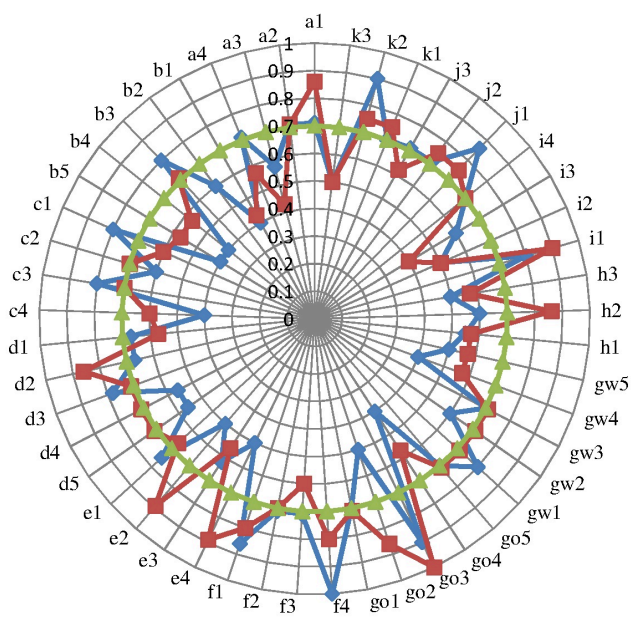

Results of Assessment Tool $1 \quad \rightarrow$ Results of Assessment Tool $2 \rightarrow-$ Target

Figure 2. Results of the Direct Assessment of Student Outcomes 
The target is the same for all SOs. The target for each performance indicator was expressed as: "The percentage of students meeting or exceeding expectations $\geq 70 \%$.

2) Indirect assessment (Senior exit survey)

The graduating student exit survey is answered by students registered at the capstone design project and their identities are kept confidential. This survey consists of three parts. The first concerns general information about the student and some information on intended employment. The second part of the survey consists of a questionnaire that is used to assess the perception that students have about their achievement level regarding the SOs (a) to (k) at the time of graduation.

The questionnaire (part 2 of the senior exit survey) has a five point scale, as follows:

1. Strongly Disagree

2. Disagree

3. Acceptable

4. Agree

5. Strongly Agree

The metric used for the indirect assessment of SOs (a) to $(\mathrm{k})$ is the percentage of answers given on the three highest points in the scale (3,4 and 5), equivalent to "Acceptable", "Agree" and "Strongly Agree".

For the indirect assessment tool, the target was expressed as: "For each question, the percentage of students scoring 3 or above $\geq 70 \%$ ".

The third part of the survey is used for collecting general opinions of graduating students of the IE Program by answering the following questions:

- What are the strengths of the program?

- What are the weaknesses of the program?

- What are your recommended changes to improve the program?

The survey provides valuable feedback for improving the program. The results concerning part 2 of the graduating student exit survey are shown in Fig. 3.

\section{Results of Indirect Assessment of SOs}

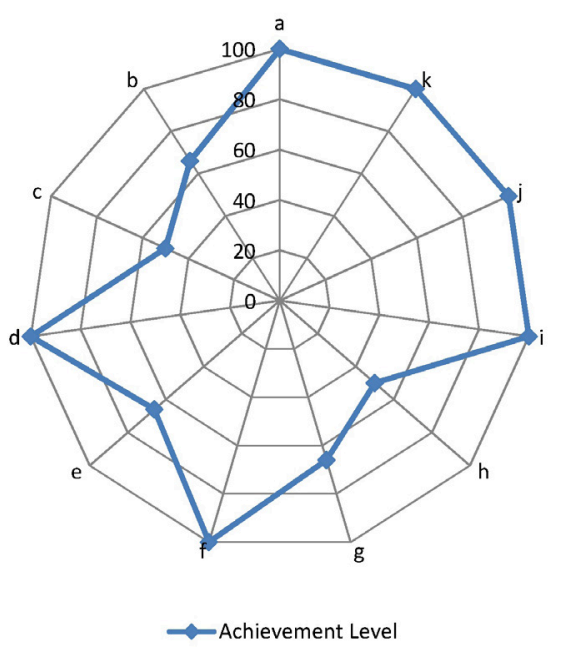

Figure 3. Results of the Indirect Assessment of Student Outcomes

\section{PROCESS OF CURRICULUM CHANGE}

\section{A. Input from Program Constituencies}

The results of the assessment and evaluation processes for the SOs reveal that the development of a new IE curriculum is essential to the continuous improvement of the program.

The development process of a new curriculum for the IE Program lasted more than one year. This process had considered all inputs from the constituencies of the IE Program as many meetings were held during the academic year 2013/2014 where the Industrial Advisory Committee of the IE Program participated as well as the representatives of Students, Potential employers, 2013 graduates, and Faculty.

The major steps followed during the development of the new curriculum of the IE Program were:

- The Curriculum Committee of the IE department suggested the draft version of the new curriculum of the IE Program

- Changes and updates were reviewed and discussed by IE Curriculum Committee in meetings with the representatives of the main.

- The IE Curriculum Committee, in coordination with the IE Accreditation Committee and the members of the IE Advisory Committee, analyzed the inputs received from the different constituencies and made a new draft explaining the reasons of the proposed changes and updates.

- Changes introduced by the Industrial Advisory Board, were discussed by the Departmental Council which approved the final version of the new IE curriculum.

Fig. 4 summarizes the development process of the new curriculum of IE Program.

\section{B. Input from ABET curriculum requirements}

The ABET curriculum requirements state that the curriculum must include [8]:

- One (01) year of a combination of college level mathematics and basic sciences.

- One and one-half years of engineering topics.

- A general education component that complements the technical content of the curriculum and is consistent with the program and institution objectives.

\section{Input from NCAAA requirements}

For the purposes of accreditation and quality reviews conducted by the National Commission for Academic Accreditation \& Assessment, 18 credit hours is the maximum that can be recognized for studies in any one semester. A minimum of 120 credit hours is required for a Bachelor's degree [9]. Credit hour calculations are based on a formula in which one 50 minute lecture, or two or three 50 minute laboratory or tutorial sessions over a 15 week teaching semester are regarded as one credit hour [9]. 


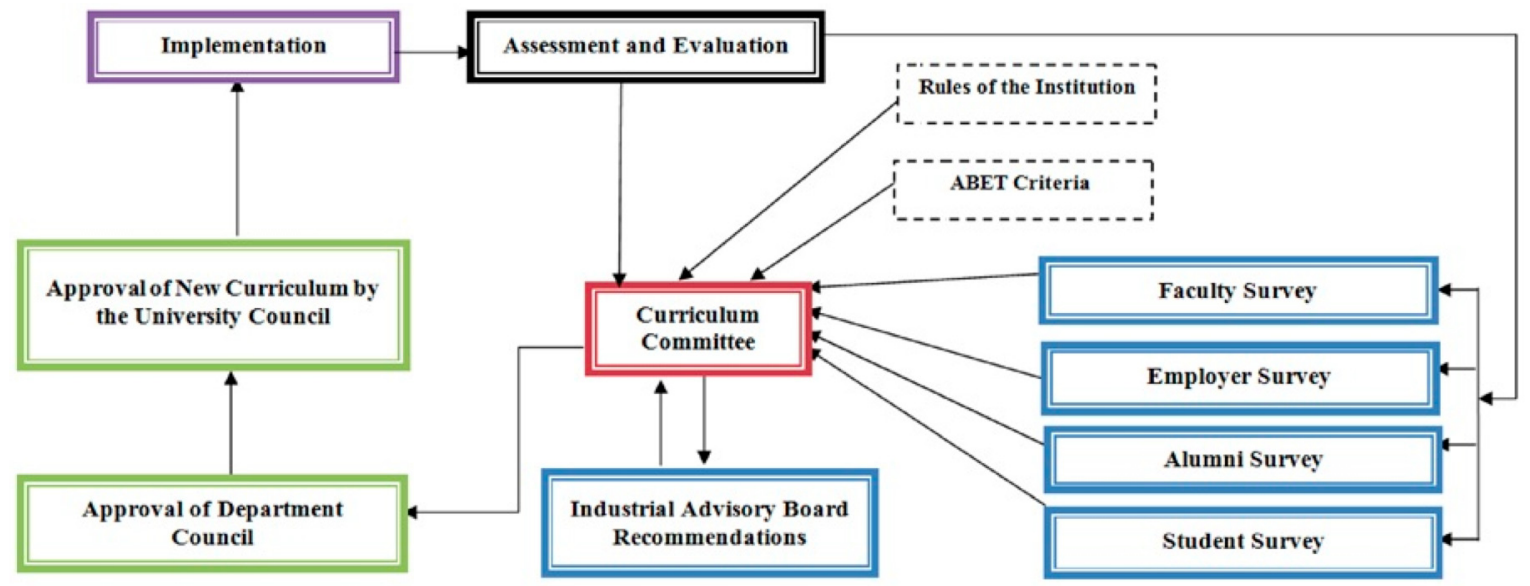

Figure 4. Process of Curriculum Development

\section{Input from the institution requirements}

Any student seeking the Bachelor of Sciences in Industrial Engineering (BSIE) degree at NBU must satisfy the following requirements:

- University requirements: aim to provide students with basic knowledge in humanities and language skills. The university course requirements include a total of 10 credit hours.

- College of Engineering requirements: consist of basic engineering sciences courses in addition to basic sciences and complementary general education courses. The college course requirements include a total of 40 credit hours.

Also, NBU has adopted a new rule that states that the Grade Point Average (GPA) earned by a student in the Preparatory Year (02 semesters) courses will not be counted in the calculation of the Cumulative GPA at the time of graduation. This new rule implies that the new IE curriculum should be built on 8 semesters instead of 10 semesters as was the case with the old IE curriculum.

Fig. 5 illustrates the impact of this rule on the fulfillment of the ABET curriculum requirements.

\section{E. Input from National Benchmarks}

Table III shows the academic rank of the best three Saudi universities within the academic top-ranking of World Universities in 2013.

These universities were selected as the national benchmark during the selection of the different courses to be included in the new curriculum of the IE Program.

\section{$F$. Input from International benchmarks}

The preparation of the new curriculum for IE Program at NBU was based on the benchmarks cited above and also on the following five programs belonging to the World's top 10 undergraduate schools in Industrial / Manufacturing where the highest engineering degree offered is a doctorate [11]:

1. Georgia Institute of Technology, Atlanta, GA (Founded in 1885)

2. University of Michigan, Ann Arbor, MI (Founded in 1817)
3. University of California, Berkeley (Founded in 1868)

4. Purdue University, West Lafayette, IN (Founded in 1869)

5. Pennsylvania State University, University Park, PA (Founded in 1855)

For each program (represented by the same \#), Table IV gives the distribution of the total of units corresponding to the undergraduate program in IE on the curriculum categories adopted by the ABET.

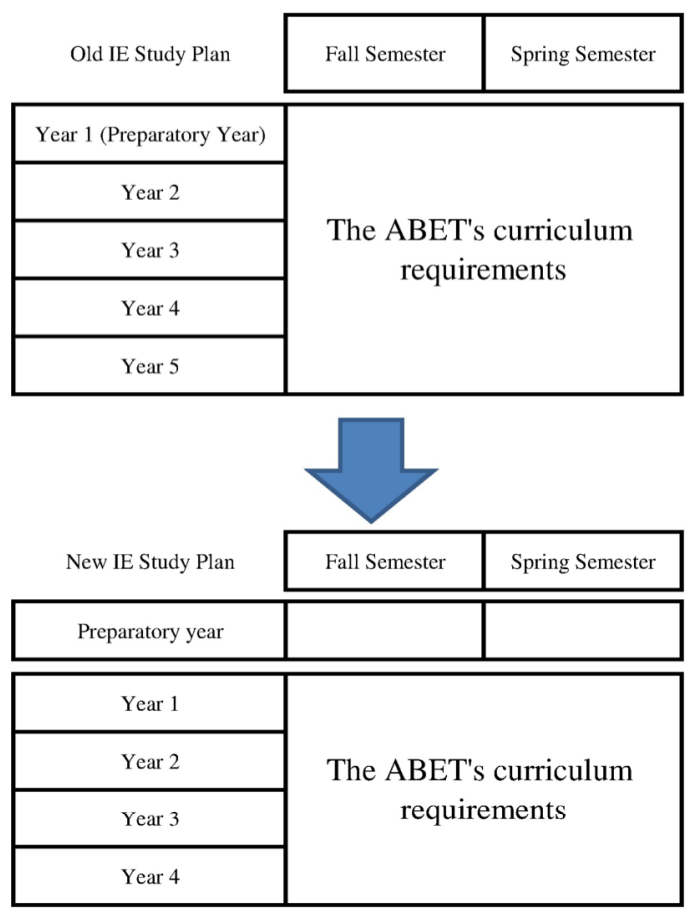

Figure 5. Meeting ABET Curriculum Requirement in 4 Years 
TABLE III.

WORLD ACADEMIC RANK OF THE BEST THREE SAUDI UNIVERSITIES [10]

\begin{tabular}{|c|l|c|}
\hline Country Rank & \multicolumn{1}{|c|}{ Institution } & World Rank \\
\hline 1 & King Saud University & $151-200$ \\
\hline 2 & King Abdul-Aziz University & $201-300$ \\
\hline 3 & $\begin{array}{l}\text { King Fahd University of Petroleum } \\
\text { \& Minerals }\end{array}$ & $301-400$ \\
\hline
\end{tabular}

TABLE IV

ABET CATEGORIES FOR 05 WORLD'S TOP 10 IE PROGRAMS

\begin{tabular}{|l|r|r|r|r|r|}
\hline Aategory & $1[12]$ & $2[13]$ & $3[14]$ & $4[15]$ & $5[16]$ \\
\hline $\begin{array}{l}\text { Math \& } \\
\text { Basic Sciences }\end{array}$ & 41 & $31-36$ & 32 & 32 & 33 \\
\hline General Ed & 29 & $19-24$ & $20-24$ & 24 & 31 \\
\hline Eng. Topics & 47 & 64 & 56 & 67 & 65 \\
\hline Free elective & 11 & 9 & 12 & NA & NA \\
\hline Total & 128 & 128 & $120-124$ & 123 & 129 \\
\hline
\end{tabular}

\section{Closing The LoOP}

During the process of continuous improvement of the IE Program, many actions have been suggested. The most important actions may be divided into three groups:

- Actions with a long implementation time (among them, the new IE curriculum )

- Actions with an average implementation time

- Actions with a short implementation time

Currently, the last phase of the cycle of improvement has not been achieved. It is necessary to re-assess and evaluate the SOs after implementing the actions proposed for improvement. This new cycle of assessment has been stated this year and will continue for two years until $2015 / 2016$. At that time, it will be possible to measure the results of the actions implemented in 2013/2014 or 2014/2015. The new IE curriculum was implemented in August 2014. .

Fig. 6 describes the timeline for implementing the different phases of the continuous improvement of the IE Program: Assess - Evaluate - Implement - Reassess.

\section{CONCLUSION}

The implementation of the review process of PEOs and assessment and evaluation processes of SOs in the IE Department at the NBU have identified a number of areas for improvement.
The most important one is the necessity for the development of a new curriculum for the IE Program that will prepare, more efficiently, the students to achieve the student outcomes upon graduation and to achieve the program educational objectives during their careers ( 3 or 5 years after graduation).

Since the program of IE is seeking ABET accreditation, it must meet all the general and program criteria particularly the ABET curriculum requirements specifying subject areas appropriate to engineering (Math \& Basic Sciences, Engineering topics and General education).

At the beginning of the development of the new IE curriculum, the ABET curriculum requirement was not the unique requirement that had been considered by the IE department. The department has also taken into account the input from the Program constituencies, requirements of the National Accreditation Commission, input from the national and international benchmarks and input from the assessment and evaluation process.

In addition to these inputs, a new rule has been fulfilled for the distribution of the courses on the years of study. Therein, the institution (NBU) has adopted a new rule that states that the grades earned by a student after the completion of the preparatory year will not be counted in the calculation of the Cumulative Grade Point Average (GPA) earned at the time the degree of Bachelor of Science is awarded. This new rule implies that the new IE curriculum should be built on 8 semesters instead of 10 semesters as was the case with the old IE curriculum.

The development by the faculty members of IE Program of the new IE curriculum is considered as evidence that the Program faculty members have responsibility and sufficient authority to define, revise, implement and achieve program objectives as required by the ABET (see [8]). By doing this, the faculty killed two birds with one stone:

- they satisfied the curricular topics required by the Program Criteria for Industrial and Similarly Named Engineering Programs (see [8]) and

- they demonstrated that the faculty have the qualifications required by the same Program Criteria cited above for IE.

\section{REFERENCES}

[1] D. A. Fowler, J.E. Froyd, and J. Layne, "Curriculum redesign: Concurrently addressing content mastery and development of cognitive abilities," 40th ASEE/IEEE Frontiers in Education Conference, USA, pp. T1H1-T1H5, October 2010. http://dx.doi.org/10.1109/fie.2010.5673605

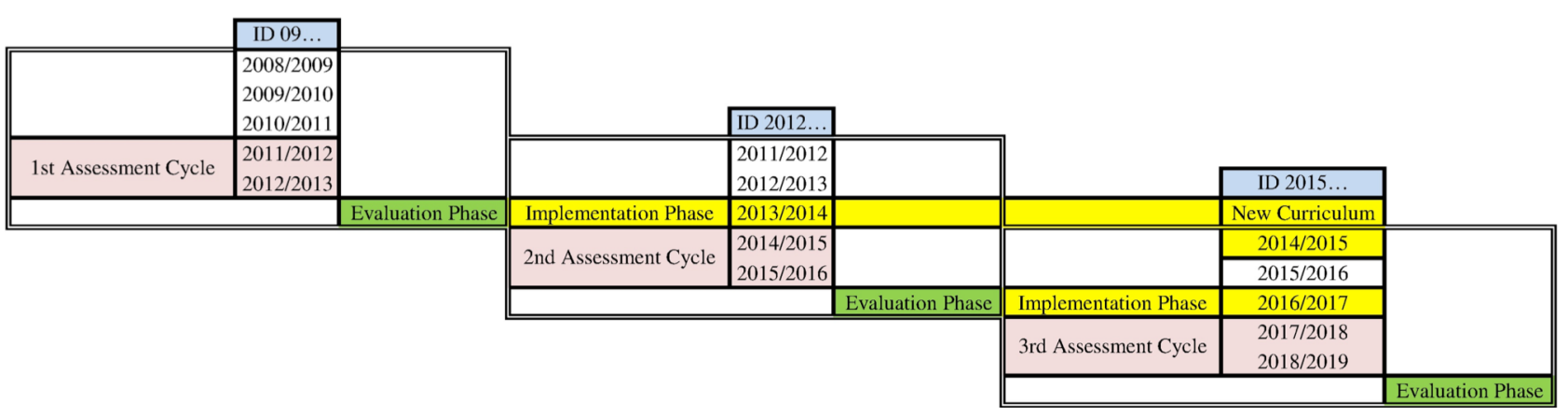

Figure 6. Timeline for the different phases of continuous improvement 
[2] V. G. Gomes, G. W. Barton, J. G. Petrie, J. Romagnoli, P. Holt, A. Abbas, B. Cohen, A. T. Harris, B. S. Haynes, T. A. G. Langrish, J. Orellana, H. T. See, M. Valix and D. White, "Chemical engineering curriculum renewal," Trans IChemE, Part D, vol. 1, 1, pp. 116-125, 2006. http://dx.doi.org/10.1205/ece.06020

[3] Z. Sari, "A New Curriculum for Manufacturing \& Industrial Engineering and Engineering Management for BS and MS Degrees," Procedia - Social and Behavioral Sciences, vol. 102, $\begin{array}{lllll}\text { pp. } & 560 & - & 567, & 2013 .\end{array}$ http://dx.doi.org/10.1016/j.sbspro.2013.10.772

[4] J. Villalobos, O. Gonzalez, C. Jimenez, and F. Rueda, "Curricula Design Model for Designing and Evaluating Systems and Computing Engineering Programs," 41st ASEE/IEEE Frontiers in Education Conference, USA, pp. S4E1-S4E7, October 2011. http://dx.doi.org/10.1109/fie.2011.6143038

[5] M. Rashid and I. A. Tasadduq, "Holistic Development of Computer Engineering Curricula Using Y-Chart Methodology," IEEE Transactions On Education, vol. 57, 3, pp. 193-200, August 2014 http://dx.doi.org/10.1109/TE.2014.2304930
[6] Terms and Definitions Used by ABET. Available in: http://www.abet.org/pev-refresher-training-module4/. Date of last access: September 10 th, 2014.

\section{AUTHORS}

Mouloud Aoudia, is with the Industrial Engineering Department, Northern Border University, Arar, Saudi Arabia (e-mail: mouloud.aoudia@nbu.edu.sa; mouloudaoudia@gmail.com).

Deya Aldeen Abu-Alqahsi, is with the Industrial Engineering Department, Northern Border University, Arar, Saudi Arabia (e-mail: dabualqahsi@gmail.com).

This article is an extended and modified version of a paper presented at the EDUCON2015 conference held at Tallinn University of Technology, Tallinn, Estonia, 18-20 March 2015. Submitted, 29 April 2015. Published as resubmitted by the authors 25 June 2015. 